\title{
Eosinophilic Colitis Masquerading as Malignancy of Colon
}

\author{
Tagore Sunkara ${ }^{\mathrm{a}, \mathrm{c}}$, Arash Samarghandi ${ }^{\mathrm{b}}$, Sriharsha Dadana ${ }^{\mathrm{b}}$, Vinaya Gaduputi ${ }^{\mathrm{b}}$
}

\begin{abstract}
Eosinophilic colitis (EC) is a rare part of spectrum of diseases called eosinophilic gastrointestinal disease (EGID). It was found to have bimodal distribution involving neonates and adults in age groups of 30 - 50 with male preponderance. We present this case of a 78-year-old woman who came to the hospital with abdominal pain, hematochezia and unintentional weight loss, and was found to have EC. This case was very unique given the age at presentation and the radiological findings mimicking malignancy. We reviewed the possible etiologies, clinical features, pathology, and treatment of EC along with the review of the literature.
\end{abstract}

Keywords: Eosinophilic colitis; Eosinophilic gastroenteritis; Eosinophilic gastrointestinal disease; Colon malignancy

\section{Introduction}

Eosinophilic gastroenteritis or eosinophilic gastrointestinal disorder is a rare chronic condition, with infiltration of eosinophils to the wall of the gastrointestinal tract. It more commonly affects the esophagus, stomach, intestine and least commonly the colon [1]. The etiology of eosinophilic colitis (EC) has not been well understood but theories suggest some association with allergy or atopic disorders. EC can also be a manifestation secondary to parasitic infections (hook or pin worms), autoimmune diseases like systemic lupus erythematosus, ChurgStrauss syndrome and drug reactions.

\section{Case Report}

A 78-year-old woman presented to the hospital with chief complaints of generalized, dull abdominal pain of 3 days duration.

Manuscript submitted June 18, 2017Manuscript submitted July 21, 2017 Division of Gastroenterology and Hepatology, The Brooklyn Hospital Center, Clinical Affiliate of The Mount Sinai Hospital, 121 Dekalb Ave., Brooklyn, NY 11201, USA

bivision of Gastroenterology and Hepatology, SBH Health System, 4422 Third Ave., Bronx, NY 10457, USA

${ }^{\mathrm{c} C o r r e s p o n d i n g ~ A u t h o r: ~ T a g o r e ~ S u n k a r a, ~ D i v i s i o n ~ o f ~ G a s t r o e n t e r o l o g y ~ a n d ~}$ Hepatology, The Brooklyn Hospital Center, Clinical Affiliate of The Mount Sinai Hospital, 121 Dekalb Avenue, Brooklyn, NY 11201, USA.

Email: tagoresunkara@hotmail.com

doi: https://doi.org/10.14740/gr878w
Patient also reported intermittent minimal hematochezia for 10 days, and unintentional weight loss of about 30 pounds over the preceding 6 months. She denied having nausea, vomiting, dysphagia or diarrhea. Her medical comorbidities included hypertension, diabetes type 2 , coronary artery disease and endstage renal disease on hemodialysis. Her last colonoscopy 8 - 10 years prior showed internal hemorrhoids.

Laboratory findings at the time of admission were significant for normocytic, normochromic anemia with hemoglobin of $8.2 \mathrm{~g} / \mathrm{dL}$ (normal range: $11-16 \mathrm{~g} / \mathrm{dL}$ ) and mild eosinophila of $0.4 \times 10^{3} / \mu \mathrm{L}$ (normal range: $0.00-0.4 \times 10^{3} / \mu \mathrm{L}$ ). Computerized tomography (CT) scan of the abdomen/pelvis showed a focal circumferential mass like thickening in colon with paracolic infiltration (Fig. 1). A diagnostic colonoscopy was performed, which showed discontiguous areas of circumferential, ulcerated, friable mucosa from hepatic flexure to descending colon (Fig. 2). The biopsies showed friable mucosa with ulcerations (not pictured) and numerous eosinophils within the deep portions of lamina propria, muscularis mucosae, and submucosa (Fig. 3). Findings were consistent with EC. Patient had complete resolution of symptoms after a short course of steroids with no complications. Patient is currently following up in the gastroenterology clinic at regular intervals with no signs of relapse.

\section{Discussion}

$\mathrm{EC}$ is the rarest form of eosinophilic gastroenteritis [2]. It is

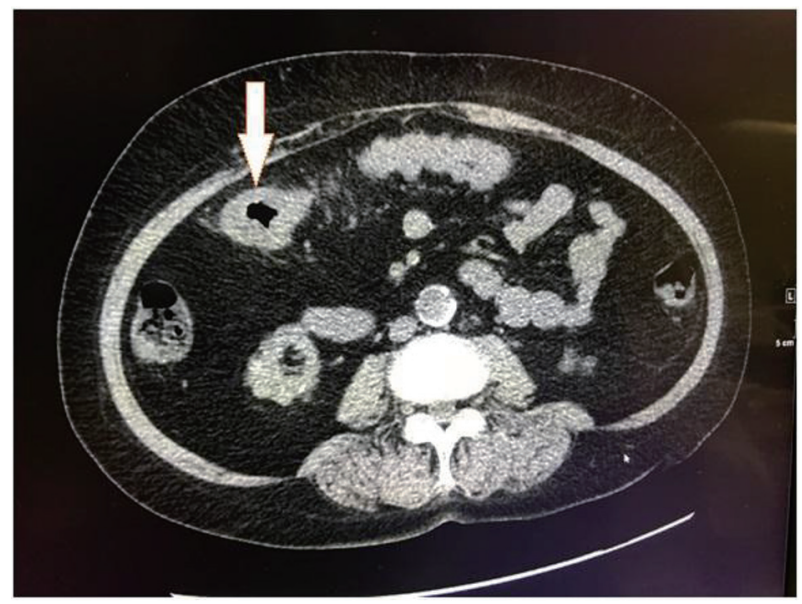

Figure 1. Computerized tomography (CT) scan of the abdomen/pelvis showing focal circumferential mass like thickening in colon with paracolic infiltration (arrow). 

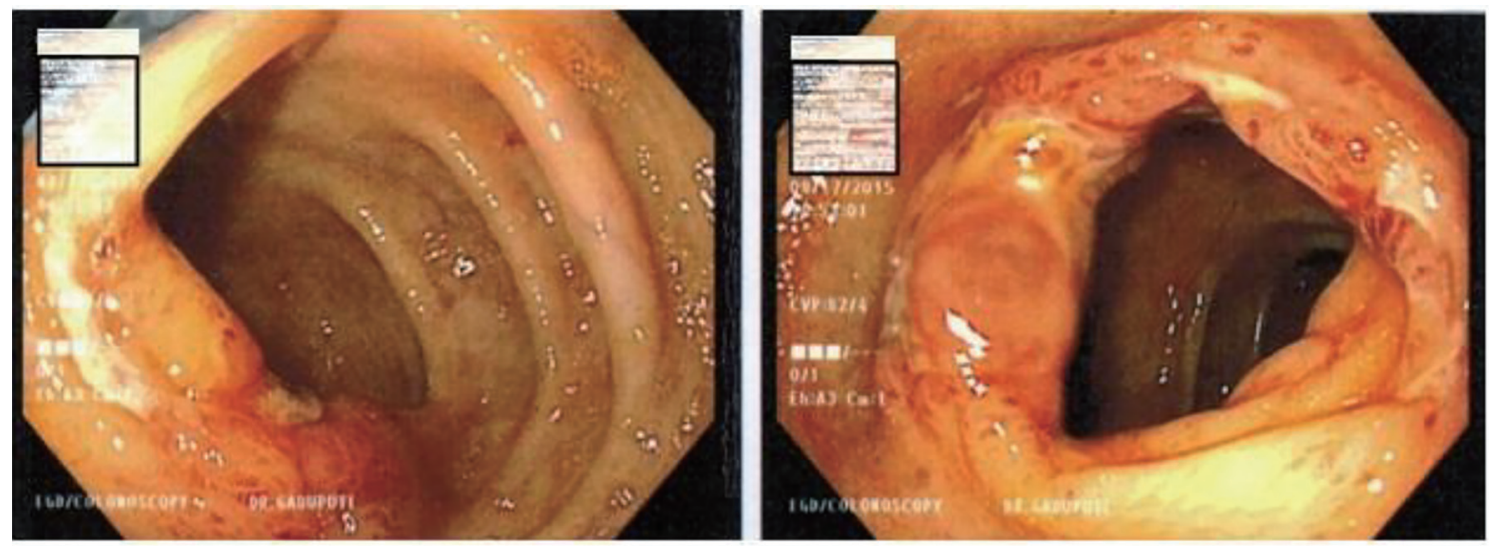

Figure 2. Colonoscopy showing circumferential, ulcerated and friable mucosa.

more commonly seen in neonates and children; however, there have been few cases of EC in adults reported commonly in third and fourth decades of life [1]. The true incidence of EC remains unclear due to its rare nature, since secondary eosinophilic gastroenteritis which can occur in conditions such as gastroesophageal reflux disease (GERD), food allergy, and inflammatory bowel disease (IBD) makes it challenging to estimate the true incidence of eosinophilic gastroenteritis. However, the estimated incidence of eosinophilic gastroenteritis is about 1 - 20 cases per 100,000 patients, with colon involvement being least frequent [3].

Even though the etiology of EC remains unclear, there are studies suggesting its relationship to food allergies, most commonly cow's milk. About $75 \%$ of patients with eosinophilic gastroenteritis have some degree of allergy or atopy; however, most of these cases are infants or neonates [4]. The clinical presentation of EC varies depending on the site and depth of the eosinophilic infiltration through the colonic wall. Symptoms include abdominal pain, nausea, vomiting, diarrhea, bleeding, weight loss, obstruction and, in severe cases, ascites [5]. Transmural disease has been reported to

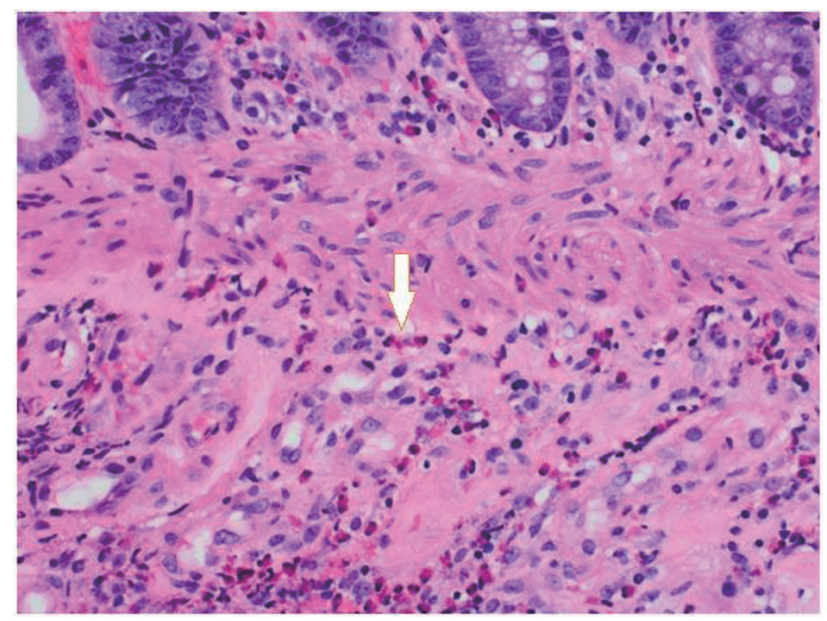

Figure 3. Biopsies showed friable mucosa with ulcerations (not pictured) and numerous eosinophils within the deep portions of lamina propria, muscularis mucosae, and submucosa. present with obstruction, intussusception, and even perforation $[6,7]$.

The diagnosis of EC is made by histology on tissue biopsies taken via colonoscopy or surgically resected specimens. On imaging, colonic distention, thickening of the bowel wall and ulcerative lesions, mimicking Crohn's disease, are some of the radiological findings [8]. On colonoscopy, signs of colitis are often evident. Mucosal erythema, edema, and ulcerated lesions are morphological findings which could be seen during colonoscopy [5].

The management of EC varies depending on the underlying condition. EC that has atopic components with peripheral eosinophilia and positive IgE caused by food allergy was shown to respond to diet restriction with resolution of eosinophilia and symptomatic relief $[9,10]$.

For other cases of eosinophilic gastroenteritis, corticosteroids remain the mainstay of therapy $[11,12]$. In most cases, improvement of the clinical symptoms is achieved within 2 - 4 weeks. However, relapses are common and require recurrent courses. There are no clear clinical guidelines on dosing or duration of steroid treatment. Often, prednisone with same dosing used in inflammatory bowel diseases is given for 4 - 6 weeks followed by tapering dose over a few weeks.

There are cases that budesonide was used with favorable outcomes. Budesonide is a synthetic oral corticosteroid, which has more local effect and low systemic bioavailability, hence it does not need slow tapering $[13,14]$. Biological agents are under investigation and anti-tumor necrosis factor (TNF- $\alpha$ ) has been used in some cases of eosinophilic gastritis, but the efficiency is not well established.

\section{Author Contributions}

Conception and design: Tagore Sunkara and Vinaya Gaduputi. Drafting of the article: Tagore Sunkara and Vinaya Gaduputi. Critical revision of the article for important intellectual content: Tagore Sunkara, Arash Samarghandi, Sriharsha Dadana, and Vinaya Gaduputi. Final approval of the article: Tagore Sunkara, Arash Samarghandi, Sriharsha Dadana, and Vinaya Gaduputi. 


\section{References}

1. Uppal V, Kreiger P, Kutsch E. Eosinophilic gastroenteritis and colitis: a comprehensive review. Clin Rev Allergy Immunol. 2016;50(2):175-188.

2. Guajardo JR, Plotnick LM, Fende JM, Collins MH, Putnam PE, Rothenberg ME. Eosinophil-associated gastrointestinal disorders: a world-wide-web based registry. J Pediatr. 2002;141(4):576-581.

3. Persic M, Stimac T, Stimac D, Kovac D. Eosinophilic colitis: a rare entity. J Pediatr Gastroenterol Nutr. 2001;32(3):325-326.

4. Rothenberg ME. Eosinophilic gastrointestinal disorders (EGID). J Allergy Clin Immunol. 2004;113(1):11-28; quiz 29.

5. Gaertner WB, Macdonald JE, Kwaan MR, Shepela C, Madoff R, Jessurun J, Melton GB. Eosinophilic colitis: university of Minnesota experience and literature review. Gastroenterol Res Pract. 2011;2011:857508.

6. Box JC, Tucker J, Watne AL, Lucas G. Eosinophilic colitis presenting as a left-sided colocolonic intussusception with secondary large bowel obstruction: an uncommon entity with a rare presentation. Am Surg. 1997;63(8):741743.

7. Fraile G, Rodriguez-Garcia JL, Beni-Perez R, Redondo
C. Localized eosinophilic gastroenteritis with necrotizing granulomas presenting as acute abdomen. Postgrad Med J. 1994;70(825):510-512.

8. Brandon JL, Schroeder S, Furuta GT, Capocelli K, Masterson JC, Fenton LZ. CT imaging features of eosinophilic colitis in children. Pediatr Radiol. 2013;43(6):697-702.

9. Bates AW. Diagnosing eosinophilic colitis: histopathological pattern or nosological entity? Scientifica (Cairo). 2012;2012:682576.

10. Jenkins HR, Pincott JR, Soothill JF, Milla PJ, Harries JT. Food allergy: the major cause of infantile colitis. Arch Dis Child. 1984;59(4):326-329.

11. Chen MJ, Chu CH, Lin SC, Shih SC, Wang TE. Eosinophilic gastroenteritis: clinical experience with 15 patients. World J Gastroenterol. 2003;9(12):2813-2816.

12. Khan S. Eosinophilic gastroenteritis. Best Pract Res Clin Gastroenterol. 2005;19(2):177-198.

13. Tan AC, Kruimel JW, Naber TH. Eosinophilic gastroenteritis treated with non-enteric-coated budesonide tablets. Eur J Gastroenterol Hepatol. 2001;13(4):425-427.

14. Straumann A, Conus S, Degen L, Felder S, Kummer M, Engel H, Bussmann C, et al. Budesonide is effective in adolescent and adult patients with active eosinophilic esophagitis. Gastroenterology. 2010;139(5):1526-1537, $1537 \mathrm{e} 1$. 